\title{
ANTICOAGULANTS IN RECONSTRUCTIVE VASCULAR SURGERY
}

\author{
By J. McCook, M.D., B. Milanés, M.D., F. Toledo, M.D., F. Castillo, M.D., P. Carrillo, \\ M.D., M. PÉREZ, M.D. and E. UGuet, M.D. \\ Staff of the Angiology Service of the 'Lila Hidalgo' Hospital, Cuba"
}

Just as the recent progress in heart surgery has occurred parallel to the improvements in the techniques of anaesthesia, so have the newer procedures in peripheral vascular surgery been helped by the development of new types and methods of administration of anticoagulant drugs in the post-operative period. At least this has been our experience in the Vascular Diseases Service of the 'Lila Hidalgo' Hospital where the basic material for this study was gathered.

In connection with this study, we have available for study the material from 24 patients, upon whom reconstructive arterial operations were performed: 18 of these were thromboendarterectomies, 2 were autogenous vein grafts and 4 were arterial homografts. We regard the result as good when the arteries remained patent, and consider the result bad when bleeding or postoperative thrombosis occurred; yet we wish to point out that in connection with this study we have intentionally ignored some other factors of no less importance, such as: selection of patients suitable for the operation and the type of operation to be performed.

At first we did not use anticoagulants in the immediate post-operative period, and based this on the following points:

I. To avoid the danger of the possible complications of this therapy, especially haemorrhage.

2. As soon as the blood flow is restored, the circulation speed increases to a rate fast enough to avoid the danger of thrombosis.

This led us to rely upon the maintenance of an adequate blood pressure and to the employment of intravenous spasmolitics (Eupaverine).

This was our procedure in three cases of iliac

*B. Milanés, M.D., Director and Chief of Clinical Service; J. McCook, M.D., Chief Surgeon; F. Castillo, M.D., Resident Surgeon; F. Carillo, M.D., Clinic Resident; E. Uguet, M.D., Intern; M. Pérez, M.D., Intern; C. Villar, M.D., Intern; J. Pérez, M.D., Intern; F. Toledo, M.D., Coagulator; R. Estrada, M.D., Pathologist; A. Garcia Plasencia, M.D., Radiologist; A. Porro, M.D., Anaesthesiologist; and R. Bustamante, M.D., Cardiologist. occlusions: one with a good result, but in the other two the artery thrombosed again at the site of the operation, which made us to think that increased circulation speed was not enough to prevent this complication.

Thus it occurred to us that the administration of anticoagulants might have an important place in the management of these patients in the postoperative period. It was only left to be proved what type of anticoagulant would be adequate and how to administer it.

Our first step was to associate heparin with anticoagulants of a prolonged action. In the postoperative period we administered intravenously heparin every four hours subsequent to the operation until coumarin anticoagulants administered several hours before the operation took the prothrombin time to adequate levels, at which point we discontinued heparin. This procedure was carried out in two cases, one of them with Tromexan, and the other one with intravenous Warfarin at $1.5 \mathrm{mg}$. $/ \mathrm{kg}$. weight. In both patients the results were disastrous due to repeated haemorrhages, even with sub-therapeutic prothrombin levels, and one patient died as a result.

It seemed possible that these coumarin anticoagulants, independent of their anti-prothrombin action and due to their capilatoxic action, had produced a diffuse haemorrhage tendency difficult to control, which made us decide that their use was counterindicated at least within the immediate post-operative period.

Thereafter we decided to administer only heparin, which we did for the first two days after the operation. In five cases we used the intravenous intermittent method with $50 \mathrm{mg}$. every 4,5 or 6 hours, according to the requirements of each particular case, with no better results because only one artery remained patent, two developed thrombosis and two other patients presented with a haemorrhage, and this was followed by thrombosis.

Our observation of these patients made us again change our course of action. We could not doubt 
the anticoagulant action of heparin. Probably the fault was in the dosage and frequency of administration. We had to accept the fact that the response to the administered dosage of heparin was not necessarily equal in every patient treated; consequently, in some of them this drug would have to be given with a more or less frequency and in more or less dosage, also. How could this situation be predetermined in order to establish beforehand a plan to follow with respect to each patient ? The only solution we could think of to solve this question was a heparin tolerance test.

After measuring the coagulation time (LeeWhite) we injected intravenously $50 \mathrm{mg}$. of heparin, then continued with subsequent measurements after Io minutes, I hour, 2 hours, 3 hours and 4 hours. Then we realized that the standard $50 \mathrm{mg}$. dosage every 4 hours, as we used to administer it previously, though in some instances sufficient in others proved to be inadequate, and in most of the patients its action ceased long before the expiration of the 4-hour period.

As this test was to be made before the operation, it was necessary to find out if the stress factor, through the adaptation syndrome of Selye, could modify it. We studied a patient upon whom we were going to make a lumbar ganglionectomy (Fig. I) and in addition to his pre-operative

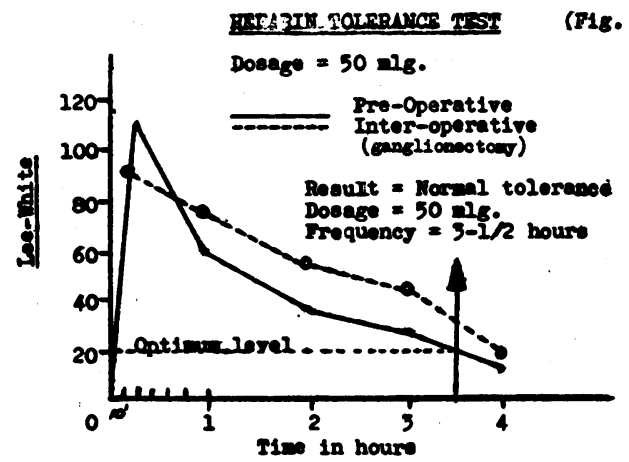

tolerance curve we made another inter-operative curve; both curves were approximately equal. This led us to think that we could have as a basis the pre-operative test to determine dosage and frequency of administration of heparin; in spite of which we were fortunate to continue our practice of both tests because in subsequent cases we realized that we were in error in making this generalization.

In Fig. 2 we pre-determined that the proper heparin dosage was of $50 \mathrm{mg}$. and the frequency of administration was one dose every $3 \frac{1}{2}$ hours. As can be seen, the coagulation time (Lee-White) in 10 minutes was raised to about 1 ro minutes, and we considered this to be a satisfactory result. Frequency was determined according to the point

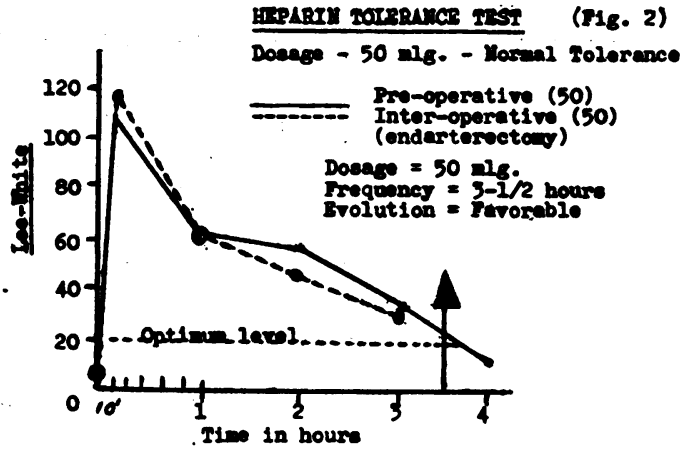

at which the optimum anticoagulant level line (in our opinion about 20 minutes) meets the tolerance curve crossing it. The inter-operative tolerance curve was similar. This patient did very well.

In Fig 3.we can see an increased heparin

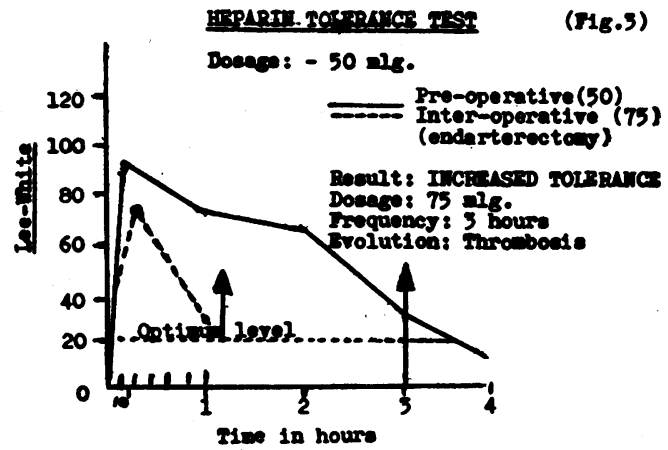

tolerance curve. The response to heparin within ro minutes was not over 85 minutes and we concluded that the correct dosage would be $75 \mathrm{mg}$. with a 3 -hour frequency. However, upon reading the inter-operative curve there was evidence of a more increased tolerance, even on a $75-\mathrm{m} . \mathrm{g}$. dosage injected before placing the provisional haemostatic clamps, to such an extent that the coagulation time after one hour was not over 30 minutes, forcing us to inject more heparin. This patient developed thrombosis.

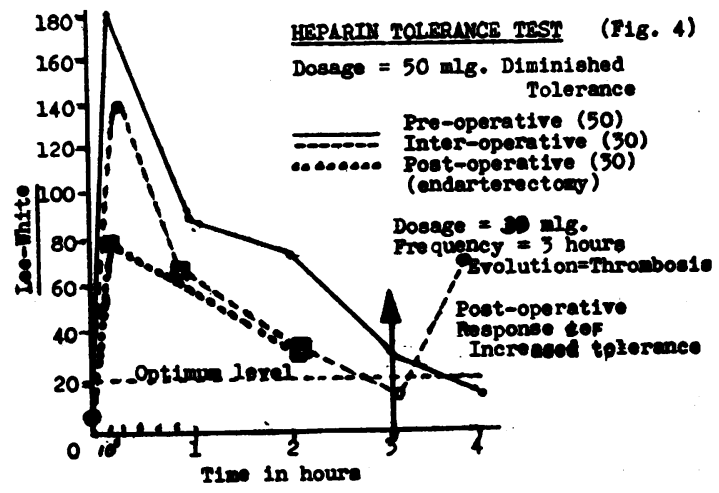




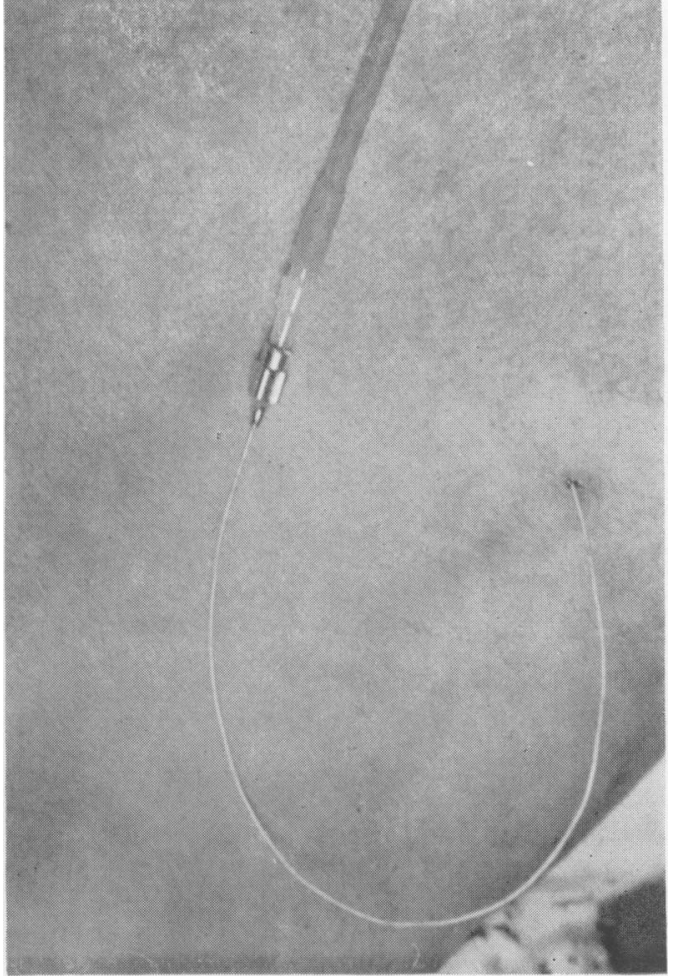

FIG. 5.-Catheter placed in aorta via the lumbar route.

In Fig. 4 is shown a diminished heparin tolerance curve. The coagulation time within 10 minutes rose to 180 minutes. In this particular patient $30 \mathrm{mg}$. with a 3 -hour frequency was considered as a good dosage. This patient developed thrombosis and a new 30-mg. heparin tolerance curve was then made, proving to us that the heparin tolerance was greatly increased.

In short, though theoretically ideal, heparin administration based on the tolerance test met in practice with the difficulty that such tolerance was much too irregular, even with respect to the same patient, as the result of not very well-known factors concerned with the intrinsic mechanism of blood coagulation which made it necessary to check tolerance frequently. This made such a procedure too uncomfortable for the patient and meticulous in the practical management for routine use. Using this method we performed the operation on four cases, two of them did well, but the other two cases developed thrombosis.

Thereafter we started to consider the regional heparinization method as described for the first time in 1938 , by Murray and Best ${ }^{4}, 5$ and later on popularized by the studies of Wylie, ${ }^{6}$ Freeman, Gilfillan, 2, 3 whose principles we have followed

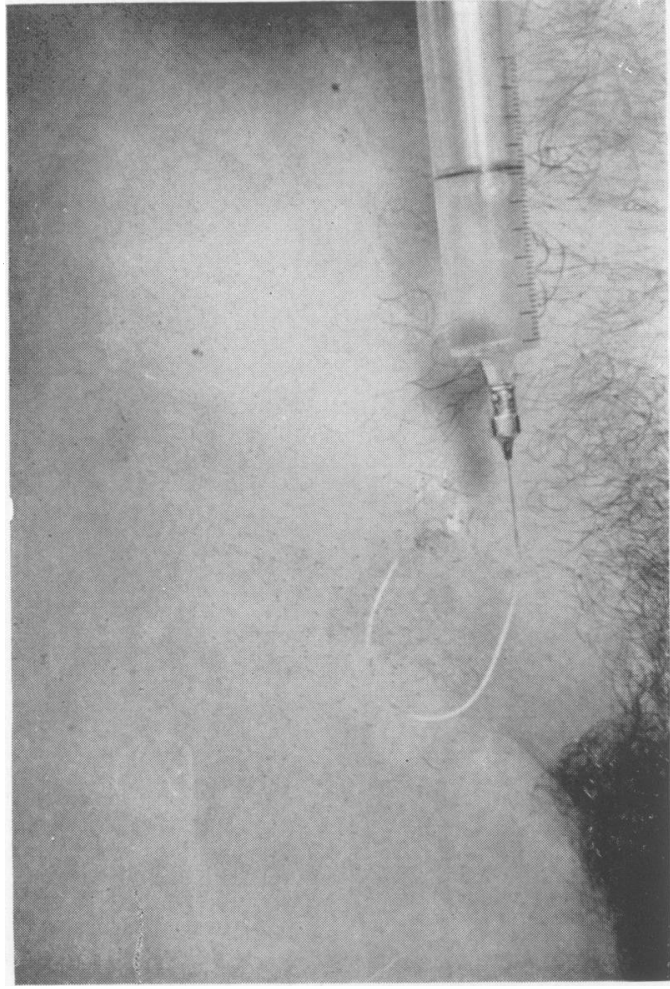

Fig. 6.-Catheter placed in the common femoral artery.

except with respect to the technique, to which, in our opinion, we have introduced useful modifications.

Our technique of regional heparinization is as follows:

(a) Before the operation we place a polyethylene or vinilite catheter in the aorta via the lumbar route (Fig. 5) or in the common femoral artery (Fig. 6) according to the site to be heparinized, by percutaneous puncture of the aorta or femoral with a B.D. No. I8-T needle after a previous local infiltration with I per cent. novocaine, keeping the catheter occluded and filled with a heparin solution until the patient is taken to the operating room.

(b) The catheter is connected by equipment of the type used for venoclasis to a flask containing a o.I per cent. solution of procaine to which we add 5 to $10 \mathrm{mg}$. per cent. heparin proportionately. A rubber circuit with a rubber bulb is then connected to insufflate air into the system in order to increase the pressure and make possible the interarterial dripping of the solution, when, after completion of the surgical repair, we remove the provisional haemostasia clamps.

(c) After the patient is back in bed the dripping 


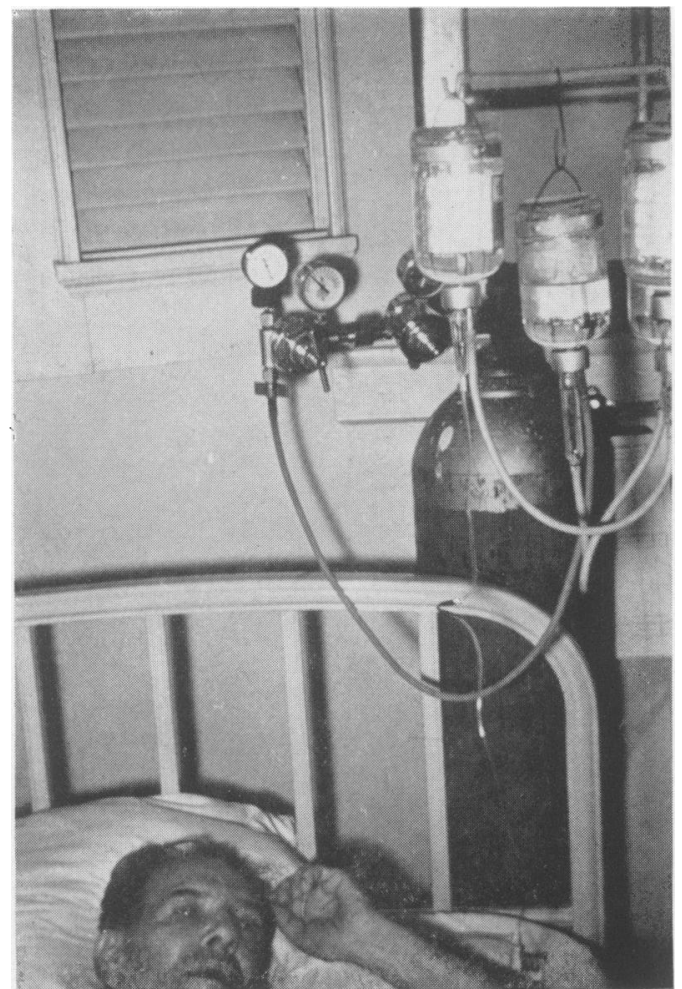

Fig. 7.-Circuit of flasks and oxygen cylinder for delivering a continuous intra-arterial drip.

of the solution can be so continued, or by connecting a circuit of flasks, containing that solution, into which pressure is exerted continuously from an oxygen cylinder, according to Degni's ${ }^{1}$ technique (Fig. 7).

(d) Regional heparinization is maintained for 72 hours. The drip rate should be such that the coagulation time of the blood in the heparinized extremity is maintained at about 20 minutes. Practically this is obtained with a speed of between I 5 or 20 drops per minute. The coagulation time in the legs and arms should be checked every I 2 hours, in order to contirm the efficiency of the method and to prevent systemic actions. The catheter should be removed six hours after the completion of the heparinization.

\section{Advantages and Reasons for Regional Heparinization}

I. The dilution of the anticoagulant in the inferior vena cava, and then in the right atrium through the inflow from the superior vena cava decreases the systemic action of the anticoagulant so that it may be used even in those patients in whom this therapy is counter-indicated.
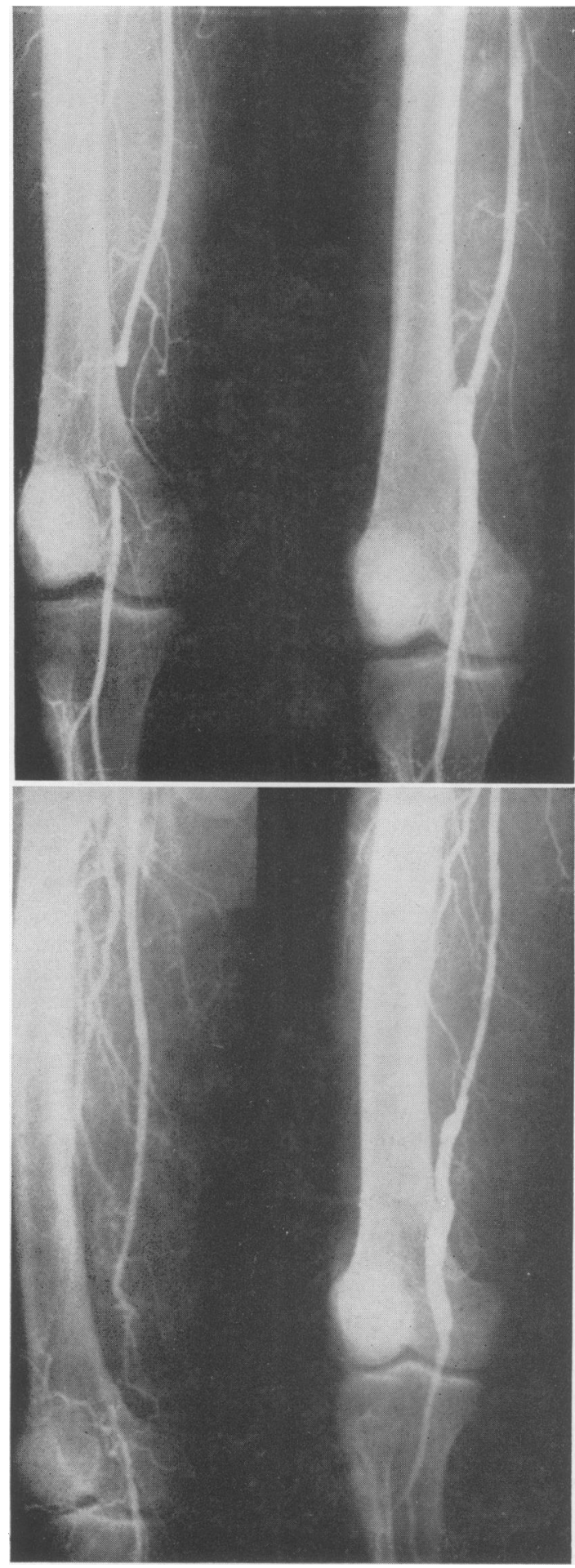

FIGS. 8 AND 9.-Segmental occlusions of femoral artery before and after autogenous vein grafts. 

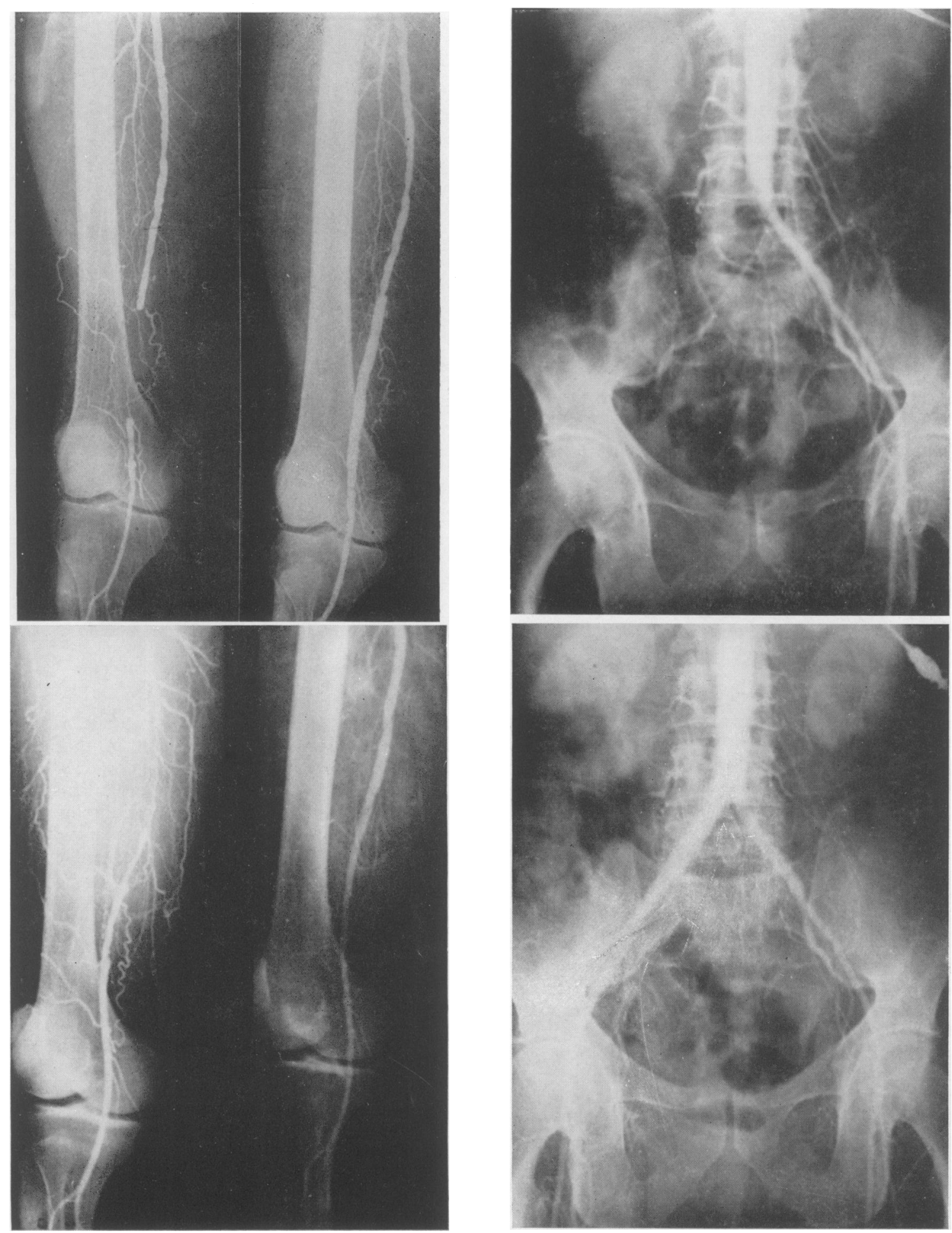

Figs. Io AND i i.- - Segmental occlusions of the femoral artery before and after thromboendarterectomy.

FIG. 12.-Right common iliac occlusion before and after thromboendarterectomy. 


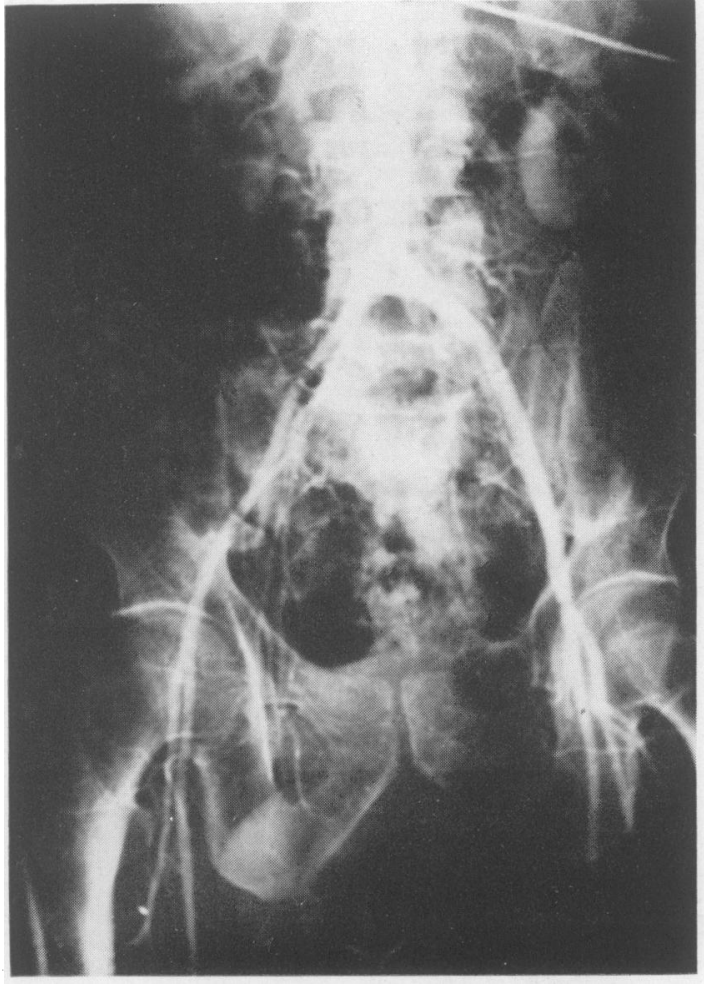

FIG. I3 (a).-Left common iliac occlusion.

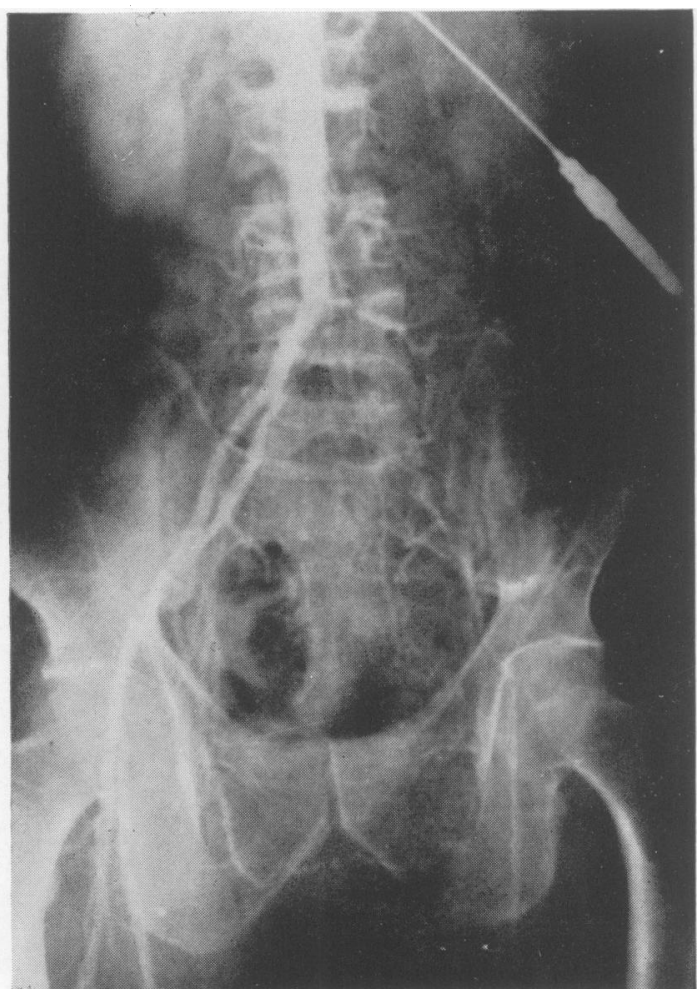

(b) Resection and replacement by an arterial homograft.
2. The technique is easy to follow and to control. 3. At the same time this technique permits the administration of water and electrolytes and also the use of antibiotics and vasodilators, thus saving the patient much trouble.

4. Results obtained have been highly satisfactory. In ten cases operated upon only one has developed thrombosis, and this did well after the re-operation.

The use of anticoagulants in vascular surgery is not limited only to regional heparinization; we also make frequent irrigations with a $10 \mathrm{mg}$. per cent. heparin solution in the area of the operation.

Regarding thrombosis prevention in the distal segment, we refuse to accept the method of simply injecting 20 or $30 \mathrm{mg}$. heparin in the distal end before placing provisional hemostatic clamps, because in our opinion it is not physiological. We regard as the ideal method the drop by drop constant irrigation by means of a polyethylene catheter introduced at the level of the distal end, but this is somewhat uncomfortable for the surgeon during the operative period. We prefer a single 25-mg. injection of heparin, after which we inflate a sphygmomanometer cuff placed just distal to the site of the operation to a pressure of $90 \mathrm{~mm}$. of mercury. This arrests the venous return, thereby holding the anticoagulant in that particular extremity throughout the operation.

We use coumarin types of anticoagulants only in patients with severe arteriosclerotic lesions as a long-term measure after the heparinization, especially if the operation was performed on the femoral or the popliteal segment.

\section{Summary}

We recommend:

I. Regional heparinization by aortic or femoral catheter as the case may be, for the first 72 consecutive hours after the operation.

2. Irrigation of the operative area with a $10 \mathrm{mg}$. percent heparin solution.

3. Heparinization of the distal area by a $25 \mathrm{mg}$. heparin injection into the distal arterial stump while we arrest the venous return by means of a sphygmomanometer cuff insufflated to a $90 \mathrm{~mm}$. of mercury pressure.

4. Coumarin anticoagulants as a long-term measure in cases of arteriosclerotic lesions, especially if they are in the femoral or popliteal sector.

References on page 394 


\section{BIBLIOGRAPHY}

ABRAHAMS, D. G., and WOOD, P. (195I), Brit. Heart F., 13, 519 BLOOMFIELD, R. A., LAUSON, H. D., COURNAND, A., BREED, E.'S., and RICHARDS, D. W., jun. (1946), $\mathcal{F}$. clin. Invest., 25, 639 .

BORST, J. G. G., and MOLHUYSEN, J. A. (1952), Lancet, ii, 304 FRIEDREICH, N. (1866), Dtsch. Arch. klin. Med., I, 241.

HALES, S. (1733) 'Statical Essays. Containing Haemastaticks: or, an account of some Hydraulic and Hydrostatical Experiments, made on the Blood and Blood-Vessels of Animals. W. Innys and R. Manby, London.

KEITH, A. (1 g08), $\dot{f}$. Anat. and Physiol., 42, I.

LAUBRY, CH., and PEZZI, C. (1913), Arch. Mal. Coeur, 6, 433.

LANCISI, G. M. (1728), 'De Motu Cordis et Aneurysmatibus,' Rome.

LEWIS, T. (1930), Brit. med. f., i, 849.
LEWIS, T. (1948), ' Diseases of the Heart,' Macmillan \& Co. Ltd., London, 4th Edition.

MACKENZIE, J. (1893), 7 . Path. Bact., 2, 84 and 273.

MACKENZIE, J. (I9O2), 'The Study of the Pulse,' Young J. Pentland, Edinburgh and London.

MORITZ, F., and VON TABORA, D. (1910), Dtsch. Arch. klin. Med., 98,475 .

MOUNSEY, J. P. D. (1955), Brit. Heart F., 17, 143.

POTAIN, P. C. E. (1867), Bul. Soc. Méd. Paris, 4,3

SZEKELY, P. (I94I), Amer. Heart F., 22, 360.

WIGGERS, C. J. (1928), "The Pressure Pulses in the Cardiovascular System,' Longmans Green \& Co., London.

WIGGERS, C. J.' (I949), 'Physiology in Health and Disease,' Henry Kimpton, London, 5 th Edition, p. 685

WOOD, P. (1950), Brit. Med. F., 2, 639 and 693.

WOOD, P. (I956), 'Diseases of the Heart and Circulation,' Eyre and Spottiswoode, London.

Bibliography continued from page 382: Surgical Endocrine Ablation for Advanced Breast Cancer

LUFT, R. (1957) Edinburgh University Lecture.

LUFT, R., and OLIVECRONA, H. (1953), $\mathcal{F}$. Neurosurg., 10, 301

LUFT, R., OLIVECRONA, H., and SJORGEN, B. (1952) Nord. med., $47,35 \mathrm{I}$.

LUFT, R., OLIVECRONA, H., IKKOS, D., NILSSON, L. B., and LJUNGGREN, H. (1956), Amer. F. Med., 21, 728

MALLARD, J. R., MCKINNELL, A., and FRANCOIS, P. E. (1956), Nature, 178, 1240.

MATSON, D. D. (I 956), Symposium on Hypophysectomy, SloanKettering Insitute. To be published.

MCKENZIE, A. (1955), Lancet, ii, I 129.

NATHANSÖ, I. R., RICE, C., and MEIGS, J. V. (1940), Amer. F. Obstet. Gynec., 40, 936 .

NICKSON, J. J. (I956), Symposium on Hypophysectomy, SloanKettering Institute. To be published.

NORTHFIELD, D. W. C. (1949), Proc. roy. Soc. Med., 42, 845.

NORTHFIELD, D. W. C. (1957), Discussion Roy. Soc. Med., March, 1957.

NOT'TER, G. (1957), Personal communication.

PATTISON, A. R. D., and SWAN, W. G. A. ( 1938 ), Lanct $t$, i, 1265.

PEARSON, O. H. (1956), Proceedings of the Fourth Conference in Steroid Hormones and Mammary Cancer, Council on Pharmacy and Chemistry, 1956.

PEARSON, O. H. RAY, B. S. WEST, C. D., HAROLD, C. C., MACLEAN, J. P., and LI, M. C. (I 954), 7. clir. Invest., 33, 956.

PEARSON, O. H, WEST, C. D., LI, M. C., MACLEAN, J. P., and TREVES, N. (1955a), A.M.A. Arch. Int. Med., 95, 357.

PEARSON, O. H. WEST, C. D., MACLEAN, J. P., LI, M. C., and LIPSETT, M. B. (1955b), Amer. Surgeon, 21, 1075.
PEARSON, O $\mathrm{H}$, RAY, B. S HAROLD C. C. LI, M. C., MACLEAN, J. P., and LIPSETT M. B. (r956), 买.A.M.A.,

PERLIA, I C. P., KOFMAN, S., NAGAMANI, D., and TAYLOR, S. G. (I956), Ann. Int. Med., 45, 989 .

RADLEY SMITH, E. I. (1957), Discussion Roy. Soc. Med.. I957. Surgical Forum, r952. Philadelphia, W. B. Saunders Co., 1953, p. $68 \mathrm{I}$.

RAY ${ }^{1953}$ B. P. (1956), Symposium on Hypophysectomy, SloanKettering Institute. To be published.

ROTH, M. (1889), Cor-Bl.f. schweitz. Aertze., 19, 146. (Cited by

Falls, 1955.)
ROTHENBERG, S. F., JAFFE, H. L., PUTNAM, T. J., and SIMKIN, B. (I955), A.M.A. Arch. Neurol. Psych., 73, 193

RUSSELL, D. S. (1956), Lancet. i, 466.

SHEEHAN, H. L., and SUMMERS, V. K (1949) Quart. F. Med.,

S'TRONG, 3.9 J. A , BROWN, J. B., BRUCE, J., DOUGLAS, M., KLOPPER, A. I., and LORAINE, J. A. (I956), Lancet, ii, 955 .

TAYLOR, S. G , LI, M. C., ECKLES, N., SLAUGHTER, D. P., and MCDONALD, J. H. (1953). Cancer, 6, 997

TREVES N (1956), Proceedings of the Fourth Conference in Steroid Hormones and Mammary Cancer, Council on Pharmacy and Chemistry, I056.

WEST, C. D., HOLLANDER, V. P., WHITMORE, W. F., RANDALI, H. T., and PEARSON, O. H. (I952), Cancer, 5,

YUHL E. T. HARPER, P. V., RASMUSSEN, T, and BERGENSTAL, D. M , Surgical Forum, r955, Chicago, W. B Saunders Co.. 1956, p. 489

References from page 388: Anticoagulants in Reconstructive Surgery

\section{REFERENCES}

I. DEGNI, M., and LANFRANCHI, W. (1954), Heparinizacao Regional: 'Vantagens o Desvantagens-Anais do Segundo Congresso Latino-Americano de Angiologia.

2. FREEMAN, L. E., WYLIE, E. J., and GILFILLAN, R. (I950), 'Regional Heparinization in Vascular Surgery,' Surg. Gynec. Obst., 90, 406, 412.

3. FREEMAN, N, E., and GILFILLAN, R. (1952), 'Regional Heparinization after Thromboendarterectomy in the Treatment of Obliterative Arterial Disease,' Surgery, 31, 1 I 5.
4. MURRAY, D. W., and BEST (1938), 'Use of Heparin in Thrombosis,' Ann. Surg., 108, $163,177$.

5. MURRAY, D. W., GORDON, and JAMES, J. M. (1940), 'Prevention of Acute Failure of Circulation Following Injuries to Large Arteries,' Brit. med. F., ii, 6, 7.

6. WYLIE, E. J., GARDNER, R., JOHANSEN, R:, and McCORKLE, $H$. (I950), 'An Experiment of Regional Heparinization,' Surgery, 28, 29, 35 .

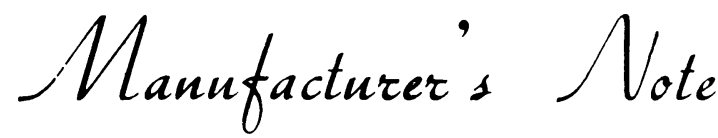

\section{SUMMER EXHIBITION}

\section{July II to August 23, 1957}

Although the Ilford Department of Radiography and Medical Photography is well known as a place of interest to the many visitors who enter its doors, this year a special effort is being made to add to its technical appeal by holding a summer exhibition.

The exhibition will include many attractive features embracing a wide range of radiographs of technical and diagnostic interest, practical demonstrations of some of the more unusual technical procedures and items of special photographic appeal.

Well-known members of the technical staff will be available for discussions and for the special demonstration features.

The exhibition, to be held at Tavistock House North, Tavistock Square, will be for all users of $\mathrm{X}$-ray and photographic materials and visitors can anticipate a cordial welcome. 